\title{
Insulin dependent diabetes in under 5 year olds
}

\author{
I G JEFFERSON, M A SMITH, AND J D BAUM
}

Children's Diabetes Clinic, University Department of Paediatrics, John Radcliffe Hospital, Oxford

SUMMARY Insulin dependent diabetes mellitus presenting in children under five years old $\frac{\bullet}{\omega}$ exhibits several clinical and management features that differ from diabetes presenting in older 0 children. In this review of the current population of the Oxford children's diabetes clinic, children $\cong$ with diabetes diagnosed aged $0-<5$ years are compared with those diagnosed aged $5-<10$ years to illustrate these differences.

The mean annual age specific incidence of diabetes for children aged $0-<5$ is $9 \cdot 9 / 100000 \vec{N}$ compared with $13 \cdot 8 / 100000$ for the children diagnosed aged $5-<10$. Although children with $\overrightarrow{\overrightarrow{\vec{H}}}$ diabetes currently aged less than 5 comprise only $8 \%$ of the clinic population, such children ultimately make up $41 \%$ of the total number of children with diabetes aged under 15 attending $ᄋ$ the clinic. Diabetes diagnosed in children under the age of 5 seems to have increased in incidence $\vec{\square}$ over the past 10 years, exhibits a male preponderence (1.5:1), and shows an unusual seasonal $\mathbb{D}$ variation in incidence with an autumn/early winter trough, late winter/early spring peak, and the absence of the mid-summer trough seen in other age groups. First degree family history was positive in $16 \%$ of children diagnosed under the age of 5 compared with $10 \%$ of the group diagnosed aged $5-<10$. In none of these children was the mother the affected relative.

Children under the age of 5 with insulin dependent diabetes mellitus constitute a small proportion of the total number of patients attending any paediatric diabetes clinic. At any time, however, almost half of the total paediatric diabetic population will have had their onset of diabetes before the age of 5 . Such children have a number of clinical features in common that may justify their consideration as a subgroup of children with diabetes, especially as they take up a disproportionately large amount of clinic personnel time in their outpatient and home management. The present study attempts to characterise this subgroup by comparing and contrasting clinical and epidemiological features of children diagnosed as having diabetes under the age of 5 with those developing the disease between the ages of 5 and 10 .

\section{Method}

In this study the notes of all children in Oxfordshire presenting with diabetes over the past 15 years have been reviewed. All such children attend a children's clinic either in Oxford or Banbury. In addition a number of children who attend the Oxford clinic live outside the district; where appropriate these children have been included in the analysis.

All children resident in Oxfordshire in the age ranges $0-<5$ years and $5-<10$ years diagnosed as having diabetes from 1 January 1969 to 31 December 1983 were identified. Various details of their clinical management were reviewed from their $\frac{\circ}{\Phi}$ records, including those children who had moved $\stackrel{\varrho}{\Rightarrow}$ out of the district or who had graduated to adult $\overline{0}$ clinics. Data from children with diabetes resident outside the Oxford health district but attending the Oxford clinic were excluded from the calculations of $\stackrel{-}{-}$ prevalence. ${ }^{*}$ Likewise those children who de- $\cong$ veloped diabetes while resident outside the Oxford? health district but who had since moved into the $\frac{3}{3}$ district were excluded from the calculations of incidence. $^{* *}$

\section{Results}

Clinic structure. At the time of the survey (31 December 1983) the children's diabetes clinics (at N Oxford and Banbury) comprised 184 children, of $N$ whom 131 were aged under 15 years. Of these 131 옹 children, 88 were resident within the Oxford district. $\omega$ All children with diabetes aged less than 15 are seen in the paediatric clinics, and the 131 children aged

*Age specific prevalence-the number of cases that exist in a community at a stated time within a defined aged range.

**Age specific incidence-the number of new cases occurring in a community over a defined period within a defined age range. $\overrightarrow{(\mathbb{D}}$ 
$0-<15$ therefore reflected the total childhood diabetes clinic population in this age range for the district.

Of these 131 children with diabetes under the age of $15,11(8 \%)$ were aged $0-<5,40(31 \%)$ were aged $5-<10$, and $80(61 \%)$ were aged $10-<15$ (Table 1$)$. Within these groups $25(62 \%)$ of the children aged $5-<10$ and $18(22 \%)$ of the children aged $10-<15$ had been diagnosed as having diabetes before the age of 5. Therefore, considering these 131 children by age at diagnosis, $54(41 \%)$ were diagnosed aged $0-<5,55(42 \%)$ were diagnosed aged between $5-<10$, and $22(17 \%)$ were diagnosed aged $10-<15$.

Thus although children with diabetes currently under the age of 5 formed only $8 \%$ of the diabetic population aged $0-<15$, cumulatively these children ultimately accounted for $41 \%$ of the Oxford clinic population under the age of 15 .

Prevalence. The age specific prevalence was calculated for children with diabetes resident within the Oxford district on 31 December 1983 using data from the Oxford record linkage study to provide the denominator of total children in the district in each age range. For the age ranges $0-<5,5-<10$, and $0-<10$, respectively, the age specific prevalence was $0 \cdot 27,0.97$, and 0.62 per 1000 (Table 2).

Incidence. The mean annual age specific incidence was calculated for all children with diabetes resident within the Oxford district at the time of diagnosis from 1 January 1969 to 31 December 1983 (Table 3). The mean annual incidence was calculated for the whole 15 year period and for the three quinquennia

Table 1 Population of Oxford children's diabetes clinic on 31 December 1983 divided according to the age groups $0-<5,5-<10$, and $10<15$ years. Each age group is divided by age at diagnosis

\begin{tabular}{|c|c|c|c|c|}
\hline \multirow{2}{*}{$\begin{array}{l}\text { Age groups } \\
\text { at } 31 \text { December } \\
1983\end{array}$} & \multirow{2}{*}{$\begin{array}{l}\text { No }(\%) \\
\text { of patients } \\
\text { at } 31 \text { December } \\
1983(n=131)\end{array}$} & \multicolumn{3}{|c|}{$\begin{array}{l}\text { No }(\%) \text { according to age group } \\
\text { when diagnosed }\end{array}$} \\
\hline & & $0-<5$ & $.5-<10$ & $10-<15$ \\
\hline $0-<5$ & $11(8)$ & $11(1(x))$ & & \\
\hline $5-<10$ & 40) (31) & $25(62)$ & $15(38)$ & \\
\hline $10-<15$ & $80(61)$ & $18(22)$ & $40(50)$ & $22(28)$ \\
\hline
\end{tabular}

Table 2 Age specific prevalence of diabetes in Oxford Health District on 31 December 1983

\begin{tabular}{lcc}
\hline Age range (years) & $\begin{array}{c}\text { No of patients resident } \\
\text { in Oxford district }\end{array}$ & $\begin{array}{c}\text { Age specific prevalence } \\
\text { per IOK) }\end{array}$ \\
\hline $0-<5$ & 8 & 0.27 \\
$5-<10$ & 29 & 0.97 \\
$0-<10$ & 37 & 0.62 \\
\hline
\end{tabular}

Table 3 Mean annual age specific incidence of diabetes within the Oxford Health District per 100000 children for age ranges $0-<5$ and $5-<10$ years, separately expressed for the 15 year survey period and for each quinquennia

\begin{tabular}{lllccc}
\hline Age range (years) & $1969-83$ & $:$ & $1969-73$ & $1974-78$ & $1979-83$ \\
\hline $0-<5$ & $10 \cdot 0$ & $:$ & 8.9 & $7 \cdot 4$ & $13 \cdot 6$ \\
$5-<10$ & 13.8 & $:$ & $11 \cdot 0$ & $16 \cdot 5$ & $13 \cdot 8$ \\
\hline
\end{tabular}

separately. There was an apparent increase in incidence of diabetes presenting in children under the age of 5 in the last five years compared with the previous two five year periods, rising respectively from 8.9 and 7.4 to 13.6 per 100000 children.

Mean annual rates of age specific incidence for each year of age considered individually from 1 January 1969 to 31 December 1983 (Fig. 1) shows a peak at $4-<5$ years as reported previously. ${ }^{1}$ Although diabetes diagnosed in the first year of life remains rare, the incidence is then fairly constant between $1-<4$ years of age at about 10 per 100000 per year.

Sex ratio. In the Oxford diabetes clinic population there is a male preponderance of 1.5 to 1 in the group diagnosed under the age of 5 and a female preponderance of 1.25 to 1 in the group diagnosed in the age range $5-<10$.

Season of presentation. Figure 2 shows the numbers of children presenting in each calendar month from 1 January 1969 to 31 December 1983 . The children

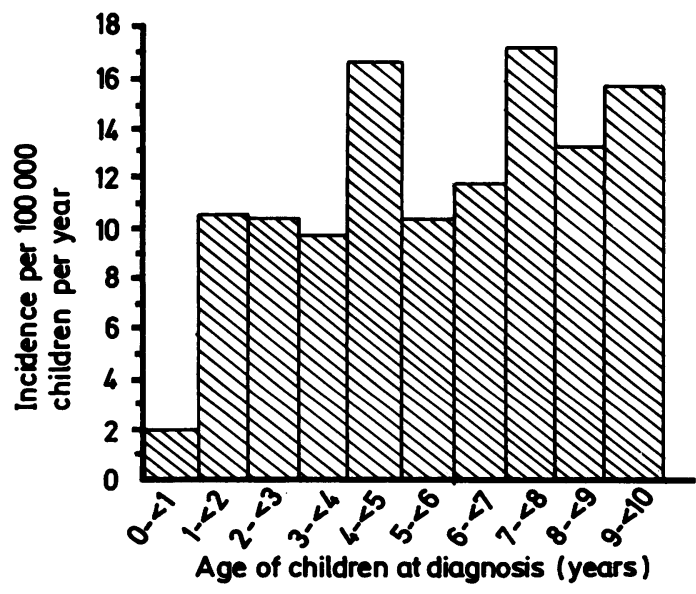

Fig. 1 Mean annual age specific incidence per 100000 children for the period 1969-83 for each year of age individually. 

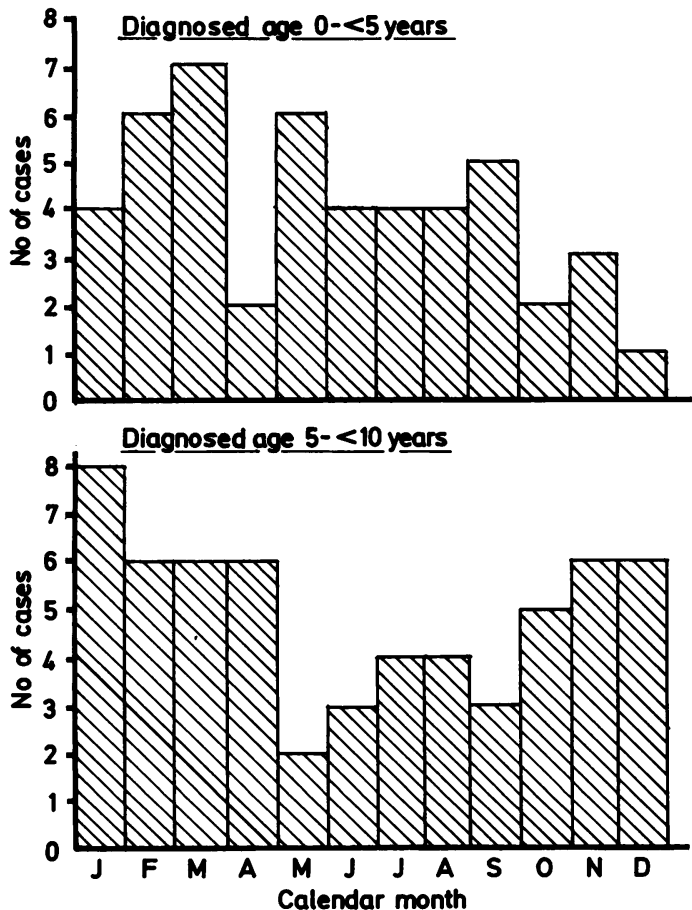

Fig. 2 Mean number of cases of diabetes by month of diagnosis within the Oxford Health District for the period $1969-83$ shown for the age ranges $0<<$ and $5-<10$ years.

diagnosed aged $0-<5$ seem to show a late winter/ early spring peak and an autumn/early winter trough. This is in contrast with the more familiar pattern seen in the children diagnosed $5-<10$, who show an autumn/early winter peak and a midsummer trough.

Family history. A family history of first degree relatives with insulin dependent diabetes was present in $10(16 \%)$ children diagnosed under the age of 5 compared with six $(10 \%)$ of the group aged $5-<10$ (Fig. 3). In the group aged under 5 the father was the affected family member in eight cases and a sibling in two; in the group aged $5-<10$ it was the father in one case and a sibling in five. In none of these children was the affected first degree relative the mother.

Where the first degree family history was negative, at least one second degree relative with insulin dependent diabetes was present in the families of 12 $(19 \%)$ children diagnosed under the age of 5 and in $14(23 \%)$ of those diagnosed aged between 5 and 10 .

History and clinical features at presentation. The clinical notes of the patients were reviewed and
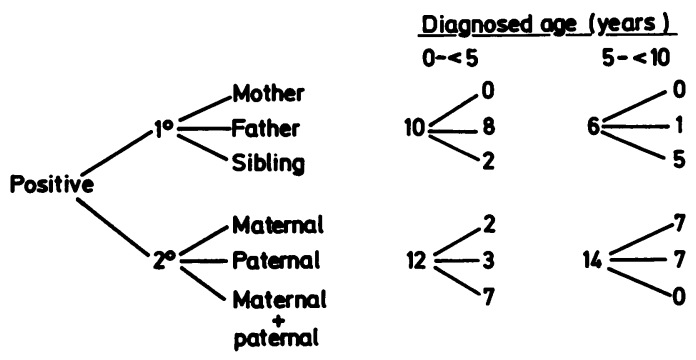

Negative

42<smiles>[R][3H]</smiles><smiles>C1CO1</smiles>

Total No

64

39

59

Fig. 3 Occurrence of first and second degree family history of insulin dependent diabetes in diabetic children diagnosed within the age ranges $0-<5$ and $5-<10$ years. Second degree family history relates to uncles, aunts, and cousins linked through mother, father, or both parents.

where available clinical details of management at presentation were noted (Table 4).

Retrospective recognisable symptoms tended to be present for a longer period before diagnosis in the older age group, with a history of symptoms of less than two weeks in $13(30 \%)$ of the group age o under 5 compared with $6(12 \%)$ of the group age $5-<10,\left(\chi^{2}=3 \cdot 1, p=0 \cdot 08\right)$. In the group diagnose aged $0-<5$ a greater proportion tended to present in ketoacidosis, and this group more often required

Table 4 Clinical features at presentation of children with diabetes in the Oxford Health District diagnosed within the age ranges $0-<$ and $5-<10$ years during the period 1969-83

\begin{tabular}{|c|c|c|}
\hline \multirow[t]{2}{*}{ Clinical feature } & \multicolumn{2}{|c|}{$\begin{array}{l}\text { No }(\%) \text { of children diagnosed } \\
\text { within each age range }\end{array}$} \\
\hline & $0<<$ years & $5-<10$ years \\
\hline \multicolumn{3}{|l|}{ Weeks' duration of symptoms: } \\
\hline $0-1$ & $6(14)$ & \\
\hline $1-2$ & $7(16)$ & $6(12)$ \\
\hline $2-4$ & $18(41)$ & $21(44)$ \\
\hline$>4$ & $13(29)$ & $21(44)$ \\
\hline Total No & 44 & 48 \\
\hline \multicolumn{3}{|l|}{ Mode of presentation: } \\
\hline Ketoacidosis & 14 (27) & $8(15)$ \\
\hline Polyuria/polydipsia/weight loss & 37 (73) & $42(81)$ \\
\hline Incidental & & 2 (4) \\
\hline Total No & 51 & 52 \\
\hline \multicolumn{3}{|l|}{ Initial treatment: } \\
\hline Intravenous insulin & $19(40)$ & 9 (19) \\
\hline Insulin subcutaneously & $28(60)$ & $39(81)$ \\
\hline Total No & 47 & 48 \\
\hline \multicolumn{3}{|l|}{$\begin{array}{l}\text { Mean duration of initial hospital } \\
\text { admission (days (SD)): }\end{array}$} \\
\hline 1 January 1969-31 December 1977 & $15(6)$ & $9(3)$ \\
\hline 1 January 1978-31 December 1983 & $6(5)$ & $4(2)$ \\
\hline
\end{tabular}


Table 5 Height centiles at diagnosis of children with diabetes aged $0-<5$ and $5-<10$. Values are number (\%)

\begin{tabular}{lcc}
\hline $\begin{array}{l}\text { Centile height at } \\
\text { diagnosis }\end{array}$ & \multicolumn{2}{c}{ Age range of children diagnosed } \\
\cline { 2 - 3 } & $0-<5$ & $5-<10$ \\
\hline$>90$ & $5(12)$ & $17(37)$ \\
$>75-<90$ & $6(14)$ & $13(28)$ \\
$>25-<75$ & $18(43)$ & $4(9)$ \\
$\gtrless 25->10$ & $6(14)$ & $8(18)$ \\
$\gtrless 10$ & $7(17)$ & $4(9)$ \\
\hline
\end{tabular}

initial intravenous treatment to correct acidosis and dehydration, $\left(\chi^{2}=4.38, p<0.05\right)$. Two of the group aged $5-<10$ were diagnosed by chance on routine urine testing for unrelated conditions.

The duration of initial hospital admission was longer in the younger children. In the past five years, however, the duration of hospital admission had been reduced in both groups, and the difference between the two groups was less pronounced.

\section{Clinical management.}

\section{Remission period}

In the group aged $0-<5$ years $16(48 \%)$ did not have any fall in insulin requirements in the months after diagnosis, nine $(26 \%)$ had a reduction of less than $50 \%$ of the starting dose, and nine $(26 \%)$ had a reduction of $50 \%$ or more from the initial stabilisation dosage. This compares with figures for the group aged $5-<10$ of $18(38 \%)$ showing no fall, 22 $(47 \%)$ a fall of less than $50 \%$, and seven $(15 \%)$ a fall of $50 \%$ or more.

\section{Growth}

The heights at diagnosis of the children with diabetes diagnosed aged under 5 were distributed as expected across the centiles (Tanner and Whitehouse, 1975). Children diagnosed aged 5- $<10$ were considerably taller than average at diagnosis with $65 \%$ of these children having height equal to or greater than the 75 th centile $\left(\chi^{2}=18.87, p<0.001\right)$ (Table 5). Growth after diagnosis was maintained in both groups with $86 \%$ and $75 \%$ of children aged $0-<5$ and $5-<10$, respectively, following their height centile at diagnosis.

\section{Discussion}

The interpretation and comparison of different studies of the epidemiology and clinical characteristics of diabetes in childhood is complicated by the different methods of ascertainment used, various age ranges quoted, and apparent geographical, racial, and socioeconomic influences. Previous data for the United Kingdom have come from birth cohort studies, ${ }^{23}$ with their acknowledged limitations, the British Diabetic Association register, ${ }^{4}$ which suffers from under reporting, and a survey of Scottish children through a record linkage study. ${ }^{1}$ In Oxford we have a well circumscribed population, and our computer based records and centralised clinic have permitted reasonable assurance of a complete survey.

Previously reported prevalence figures for the British Isles vary. Henderson, in a survey of cases in England in 1947, found an age specific prevalence of 0.005 per 1000 for children aged $0-<5$ and 0.13 per 1000 for children aged $5-<10 .^{5}$ Two birth cohort studies have quoted prevalence figures at particular ages: the National Child Development Study (195874) 0.26 per 1000 at age 7 and 0.58 per 1000 at age $11,{ }^{2}$ and the Child Health and Education Study (1970-80) 0.36 per 1000 at age 5 and 1.3 per 1000 at age $10{ }^{3}$ The rates of age specific prevalence for the Oxford health district are comparable with the two most recent birth cohort studies. The prevalence of diabetes in the age range $0-<5$ is about $25 \%$ that in the age range $5-<10 ; 62 \%$ of the children with diabetes now aged $5-<10$, however, had their disease diagnosed under the age of 5 .

Incidence is more difficult to measure accurately as it requires the long term surveillance of a large cohort of children or the study of a comprehensive set of records from a geographically well defined population. Moreover, there are wide geographical, racial, and socioeconomic variations in the incidence of the disease. In the British Isles reports of annual rates of incidence in childhood have varied from $7 \cdot 6^{5}$ to $13 \cdot 8^{1}$ per 100000 . A recent study of Scottish children ${ }^{1}$ has shown an average annual incidence of 7.2 per 100000 in children aged $0-<5$ and 11.4 per 100000 in children aged 5-<10. The mean annual rates of incidence in this study are comparable with recent published studies. None of the previous reports suggest the apparent increase in incidence in diabetes among children aged $0-<5$ seen in Oxford.

Reviewing the data from previous studies, there is a trend towards higher incidence and prevalence figures in more recent studies. Two studies in particular have suggested an increasing incidence of onset of diabetes in childhood: Stewart-Brown et al compared rates of prevalence in three successive birth cohort studies and showed a significant linear trend over the three periods separated from each other by a decade or more; ${ }^{3}$ and Patterson et al, using a computer file of all admissions to Scottish hospitals, showed an $80 \%$ increase in incidence over nine years (1968-1976: age range $0-<19$ years). ${ }^{1}$ Our study shows a linear trend of increasing incidence over 15 years, which just fails to reach 
significance at a $5 \%$ level using a Cox-Stuart test for trend and is accounted for almost entirely by the group aged $0-<5$, although numbers are too small to draw firm epidemiological conclusions.

We have found a male preponderance of diabetes in those aged under 5 and a female preponderance in the $5-<10$ year olds; this confirms the findings of the British Diabetic Association register reported in $1975 .{ }^{4}$ Other studies have varied in their findings with no agreed pattern emerging. ${ }^{1-4}$

Previous reports of the seasonality of presentation of childhood diabetes have shown a peak in incidence in autumn (September-October) and in winter (December-March) with a trough in midsummer (June-July). ${ }^{14}$ Any seasonal variation has previously been noted to be absent in children developing the disease aged under 5. In Oxford the seasonal pattern is confirmed in the group diagnosed aged $5-<10$, but in addition there seems to be a seasonal variation in the group aged $0-<5$. (Fig. 3). The later peak and trough in these younger children could reflect a delay in the time to diagnosis, assuming common aetiological and seasonal effects.

There was a positive first degree family history in $16 \%$ and $10 \%$ of the children diagnosed aged under 5 and between $5-10$, respectively. This is broadly in agreement with previous reports from the British Isles of a first degree relative in $11 \%,{ }^{4} 13 \%,{ }^{8}$ and $23 \%^{2}$ of patients, although these other studies covered a wider age range and did not subdivide subjects by age at diagnosis. A striking finding in this survey is the absence of mothers with insulin dependent diabetes among families with diabetic children aged under 10. A lower incidence of a maternal history of diabetes has also been noted recently in two other studies. In a six year prospective study of all Swedish diabetic children aged 0-15, the father was the affected family member twice as commonly as the mother, although the children's age ranges were not subdivided. ${ }^{6}$ Similarly, a survey of patients at the Joslin diabetes centre has shown that fathers with diabetes have a fourfold greater risk of producing a diabetic child than mothers with the disease. ${ }^{7}$

Children diagnosed as having diabetes aged $0-<5$ seem to present more acutely than those diagnosed aged $5-<10$ as shown by both the shorter duration of retrospectively recognisable symptoms and the higher incidence of ketoacidosis at presentation. This may reflect a differing aetiology or pattern in the decline of pancreatic function, an increased incidence of unrelated intercurrent infection precipitating ketoacidosis, a general increased risk of dehydration in the younger smaller child, or a delay in diagnosis perhaps resulting from the general belief that diabetes is very rare in young children. In the past five years the time spent as an inpatient after diagnosis has been reduced; this may reflect improved understanding and management, particularly in the younger child, together with a change in $\frac{0}{0}$ emphasis towards community based care and educa- 음 tion. It does not, however, seem to reflect earlier $\frac{\bar{m}}{T}$ diagnosis, as the incidence of ketoacidosis at diag- $\frac{\mathbb{\alpha}}{\mathrm{Q}}$ nosis has not declined over the same period.

Diabetes in a small child places considerable stress on the family in terms of daily injections, $\stackrel{\circ}{\circ}$ dietary management, recognition of hypoglycaemia, $\overrightarrow{\vec{\omega}}$ and coping with frequent intercurrent illness, which $\stackrel{\sigma}{\omega}$ is a normal feature of life in young children. We have found it useful to establish a separate toddler clinic, allowing time for group discussion among 8 parents when they can share worries with others in a $\vec{N}$ similar position.

Diabetes in the young child is not rare and seems to show some clinical and epidemiological differences from diabetes in older children. As such it warrants particular investigation as it may offer the possibility of an aetiological understanding that may be different from or clearer than that which applies to diabetes with onset at later ages.

We thank Dr R A F Bell and Dr H Marcovitch for permitting access to the case notes of children with diabetes attending the Banbury children's diabetes clinic. We also thank Dr M Goldacre. for his help in supplying data from the Oxford record linkage stude Mr David Rees (senior lecturer, Oxford Polytechnic) for statisticat advice, and Miss Belinda Moss for preparation of the manuscript. IGJ was in receipt of an Oxford Regional Health Authority off service year and Novo research fellowship.

\section{References}

${ }^{1}$ Patterson CC, Thorogood M, Smith PG, Heasman MA Clarke JA, Mann JI. Epidemiology of type I (insulindependent) diabetes in Scotland 1968-1976: evidence of an increasing incidence. Diabetologia 1983;24:238-43.

2 Calnan M, Peckham CS. Incidence of insulin-dependent diabetes in the first sixteen years of life. Lancet 1977;i:589-90.

${ }^{3}$ Stewart-Brown S, Haslum M, Butler N. Evidence for increasing prevalence of diabetes mellitus of childhood. $\mathrm{Br} \mathrm{Med} \mathrm{J}$ 1983;286:1855-7.

${ }^{4}$ Bloom A, Hayes TM, Gamble DR. Register of newly diagnosed diabetic children. $B r$ Med $J$ 1975;iii:580-3.

${ }^{5}$ Henderson $P$. Incidence of diabetes mellitus in children and need for hostels. Br Med J 1949;i:478-9.

${ }^{6}$ Dahlquist G, Gustavsson KH, Holmgren G, et al. The incidence of diabetes mellitus in Swedish children 0-14 years of age. Acta Paediatr Scand 1982;71:7-14

7 Warram JH, Krolewski AS, Gottlieb MS, Kahn CR. Differences in risk of insulin-dependent diabetes in offspring of diabetic mothers and diabetic fathers. $N$ Engl $J$ Med 1984;311:149-52.

${ }^{8}$ Oakley WG, Pyke DA, Taylor KW. Clinical diabetes and its biochemical basis. Oxford: Blackwell, 1968

Correspondence to Dr I G Jefferson, Children's Diabetes Clinic, University Department of Paediatrics, John Radcliffe Infirmary, Oxford.

Received 29 July 1985 